\title{
Evaluating Computer Aided Design Tools for Building Performance: Trusting and Defining the Predetermined Automated Inputs
}

\author{
E.R. NEWMARCH ${ }^{1}$, N. BAKSHI ${ }^{2}$, M. DONN ${ }^{3}$ \\ 1,2,3 Victoria University of Wellington, New Zealand.
}

\begin{abstract}
BIM use is on the rise in New Zealand with popular software packages, including Revit and ARCHICAD, adopting a semi-automated simulation platform. This allows architects and designers to calculate the thermal and energy performance of their designs. This paper identifies the strengths and weaknesses of these semi-automated simulation platforms. The objective is to investigate how accurate their assumptions are in determining a reliable output for use in achieving compliance with Clause $\mathrm{H} 1$ of the New Zealand Building Code. To achieve this, this paper reports a comparative study that examines the program's ability to calculate construction $R$-values, interpret thermal properties and simulate energy performance. The results from this study show that if used as delivered there is a significant difference between the simulation results of the two software packages, due to the assumptions built into the default settings. It also identifies the disadvantages of the inbuilt construction $R$-value calculators and explores a potential path to resolving this through redefining the inputs of thermal properties.
\end{abstract}

KEYWORDS: Energy Simulation, BIM, Efficiency, Residential

\section{INTRODUCTION}

The fourth annual BIM Benchmark Survey in a 5year series completed as part of a BRANZ (Building Research Association New Zealand) study, identifies that 57 per cent of all construction projects adopt the Building Information Modelling (BIM) approach over traditional methods [1]. This percentage is expected to rise following the exponential implementation trend over recent years [1]. The widely-used software packages within the construction industry, that support the BIM methodology, are ArchiCAD and Revit [2]. Their BIM functionality converts them into semiautomated building energy performance simulation platforms that aim to eliminate inappropriate human intervention that could cause results to be untrustworthy [3]. Instead of early design performance prediction based upon rules of thumb developed using predetermined prototypical performance they offer performance simulation inputs that are automatically assigned to increase workflow productivity. This paper investigates these simulation inputs and the accuracy of building energy performance simulation from these different widely used BIM software packages. This paper specifically focuses on how such BIM packages could be used to evaluate energy and building performance for producing evidence for compliance documentation. This is a major area of investigation yet to be explored because building energy performance simulation is, to date, one of the least used assets of these software packages, with only 14 per cent of the industry using BIM for this purpose, compared to 91 per cent which use it for 3D coordination [1]. Current trends also identify a significant decline in the number of projects that use BIM to demonstrate code compliance, down to 0 per cent in 2017 from 9 per cent in 2016 [1]. There appears to be a significantly underutilised potential for a BIM based workflow in the New Zealand Industry.

The focus is the viability of BIM adoption in the residential market, where architects and designers are the target users. In this context, architects and designers are often solely responsible for ensuring the energy and thermal performance of the building meets the minimum building code, as there is rarely the money nor time available to out-source this task. Furthermore, the New Zealand Building Code [4] offers three potential methods of compliance: schedule, calculation and modelling methods. The first two disconnect the project from the BIM workflow as they both require a manual calculation of the thermal performance of each individual building component (floors, walls, roof etc.). The modelling method, however, presents the opportunity to remain within the BIM workflow and has the potential to achieve higher efficiency in demonstrating code compliance. The parameters of this method form the basis for the assessment of the ability of BIM-enabled software to demonstrate this compliance with a good measure of accuracy.

\section{BACKGROUND}

The interest and importance of simulating energy and building performance has grown in the architectural design industry due to the increased awareness of energy usage on building life cycle costs 
and the impact of indoor environment conditions [5]. However, the ability to complete these predictions is weakened through simplistic and optimistic calculations prescribed by the building code to accommodate architects and designers. Sophisticated software, outside the BIM approach, has had the capability to create accurate predictions of building energy performance for decades. This software has not been widely adopted by practitioners in building design for many reasons [6]. Instead it is more commonly used for academic research [5]. Alternatively, BIM has become a promising development for the future of architecture, engineering, and construction. It has the advantage of creating a virtual (digital) version of the proposed building that has a wide variety of uses from planning to operation of the building. Yet, as a developing workflow, it also has issues getting practitioners to incorporate energy and building performance methodologies.

A paper investigating a library for energy and building performance in BIM, suggests that the BIM enabled interoperability between architectural design and energy simulation actually prevents energy analysis becoming an efficient process in the early stages of design [7]. The paper proposes an Object Orientated Physical Modelling (OOPM) approach that could produce component level simulation results which allow direct feedback to the designer of the impact on energy performance of building design decisions about individual building components. The benefit is the ability to visually link the results from the energy and building simulation directly to the virtual design, showing potential for implementation within practice.

Another paper identifies numerous sources that suggest building energy performance simulation is seldom implemented in practice due to the associated labour intensive and costly processes [2]. In contrast, the semi-automated processes adopted by various CAD packages may reduce such costs. For these automated inputs to be trusted, their outputs need to be validated against known information. To be used for Code Compliance in the NZBC, Clause H1 "Energy Efficacy for housing and small buildings" these outputs also need to be converted into a format that is accepted and recognised by district councils, so that they can contribute as evidence for compliance.

\section{METHODOLOGY}

The NZBC "Modelling Method" requires submission of a compliance report comparing the performance of a simulated model with a reference model. The reference model is built to the compliance requirements outlined in NZS 4218. This model applies the minimum construction $\mathrm{R}$-values for the relative climate zone and is considered the minimum level of performance.
To investigate the consistency of common BIMenabled software packages, this paper adapts this process and presents the building energy performance results of a reference model, a proposed model and a model using software inputs. As a measure of quality assurance all models use the same geometry and glazing ratio.

The "Reference Model" uses the simple R-values specified in the NZS4218 Standard [8]. The "Proposed Model" applies construction R-values calculated using the "isothermal planes" method specified in NZS 4214 [9]. These R-values account for the thermal bridging of the actual materials used in the building structure. They are therefore the targets for determining the accuracy of the software. The "Software Input Model" models' results are compared to the Proposed and Reference models.

In both software packages, models were built using material descriptions that align closely with the building's consent specifications. For example, Pink Batts (C), a glass fibre batt insulation product commonly used in New Zealand construction, has been matched with the glass fibre batt insulation option in both ARCHICAD and Revit. Additionally, the default occupancy schedules and heating/cooling loads of a typical residential building were used to examine the difference in assumptions made by both software packages.

To test the ability of the inbuilt construction Rvalue calculator in each property, construction assemblies were made using materials present within the inbuilt library. Each material layer was given the same thickness to match the case study construction specification. However, as both inbuilt calculators were homogenous, for heterogeneous layers the most prevalent material properties were taken. In the context of this case study, in an insulated timber wall with a timber structure and insulation infill between the vertical timber studs, a single insulation material "layer" was defined. As a combination of the two materials' R-values. The methodology for R-value inputs for the reference and proposed models differ slightly in each software due to their interface and settings. These are differences are outlined in the following sections.

\subsection{Modelling in ARCHICAD}

For the reference and proposed simulations, the construction R-values were input using the override setting within the energy model evaluation settings and the appropriate "Structure Heat Storage Mass" was applied [10].

\subsection{Modelling in Revit}

For the reference and proposed simulations, the construction R-values were input by creating a new material with thermal properties that generated the reference and proposed construction R-values. 


\section{INVESTIGATED BUILDING TYPE}

The standalone single family housing is the most dominant housing typology ( $80 \%$ ) throughout New Zealand [11]. For this reason, a standalone typology has been selected for this research.

As the focus is on how well the software interprets and calculates the specification of building, a simplified case study has been selected. Construction assemblies represent the most common used systems in New Zealand residential construction. Walls and roofs are framed with timber + pre-nail manufacturing. Floor on ground is a concrete slab with polystyrene insulation (insulation under slab is increasingly more common in the south).

Detached single family houses have historically been the dominant housing typology in the Queenstown Lakes District. However, more recently there has been increasing demand for more affordable housing. The common answer, applied nation-wide, is to look towards medium density housing, to provide a lower upfront cost to the housing market. Yet, a recent housing preferences survey revealed that standalone housing scored consistently higher then attached, medium density, and high rise living, on perceived factors including; value for money, neighbours that are safe, have an enjoyable lifestyle, a good sense of community, and are visually appealing [12]. This strong desire to continue living in standalone, sole ownership, housing is feeding the rise of an increasingly popular typology of a main house and guest house on a single property title. Derived from a multi-family housing model, this typology has been edited to create a house and income model, which allows the owner to rent out the guest house to pay the mortgage on the full property. As Queenstown is a high tourism area, popular business apps such as AirBnB and HelpX, enable this housing typology's success and attractiveness. For these reasons a house and guest typology has been selected for this study.

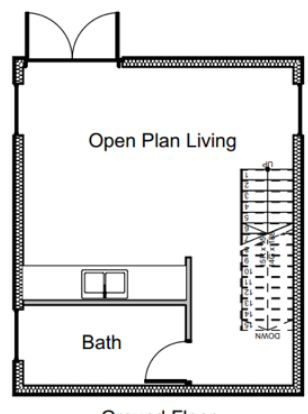

Ground Floor

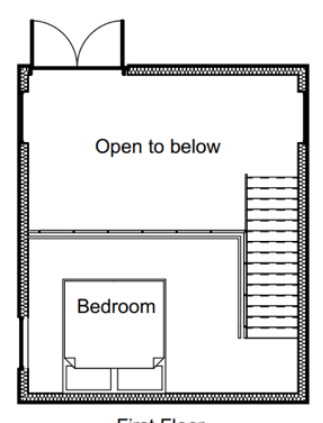

First Floor
Figure 1: Case Study Floorplans

\section{RESULTS}

Initial simulations suggested that there is a significant identifiable difference between the outputs of each CAD package. These results drew attention to the assumptions made by the automated inputs to the software. This study found that certain defaults have an appropriate place within the semi-automated simulation process, however, other pre-set inputs within the software could be improved to more adequately respond to New Zealand's building regulations, conditions, and climates. The end of this study examines the various observations between real world figures and the simulation findings of both the simulation methods explored, identifying variations in the semi-automated processes used by each CAD package that informed the numerous inputs.

\subsection{Results - Building Component Construction Inputs}

In energy simulation, it is essential to have reasonably accurate inputs for the thermal properties of the building's external envelope. These inputs are important as they can greatly impact the building's heat loss as well as the annual energy consumption.

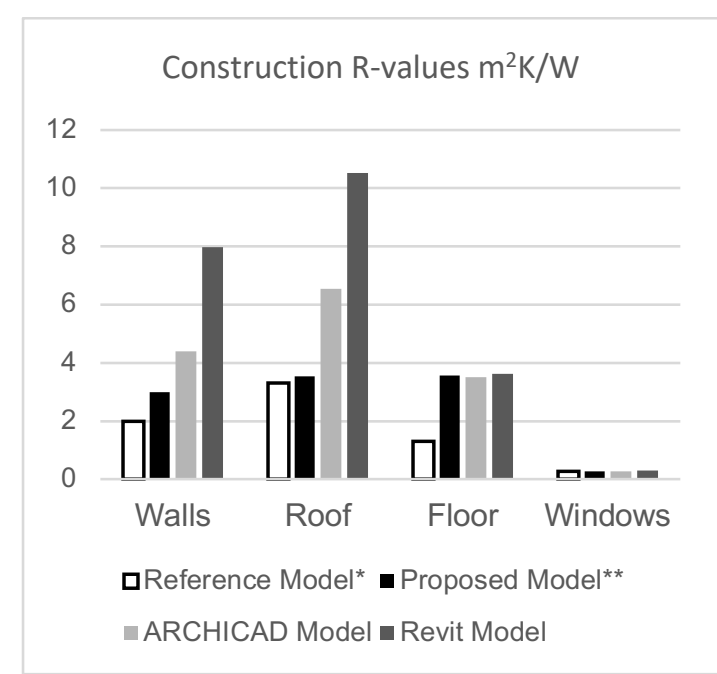

Figure 2: Construction R-value Calculations

*Minimum R-values based on Table 2 in NZS4218 for Climate zone 3

**Construction R-values calculated using the approved Iso-thermal planes method outlined in NZS 4214. These figures are considered a target for testing the software ability to calculate R-value's accurately.

The calculations shown in Figure 2 identify that there is significant variation in the software's ability to calculate accurate construction R-values for the walls and roof. Yet, there is consistency shown in the results for the floors and roof. This identifies that, such a simulation process is limited to only homogenous construction build means that the calculation can only account for a single material per layer.

This is an issue because the most common types of construction in New Zealand have at least one heterogeneous layer that is host to insulation placed in-between the timber structure. It is understandable that both the semi-automated simulation software packages would simplify the construction R-value calculation to only include a homogenous build up due to the manual requirement of setting the appropriate 
percentages. However, by not allowing this flexibility in the calculation the results are unreliable and optimistic. This level of optimism can be costly as it gives a false representation to the architect or designer which could lead to compliance being awarded incorrectly. Ultimately, making generous assumptions in the simulation stage of a project only decreases the quality of the built product. Material libraries in both programs do not include materials that are within an acceptable range to be considered an accurate representation of the true material.

A potential solution would be either create a material library that is included in the software package for New Zealand. Alternatively establishing a format where products can supply a schedule that can be imported into the software could also be an opportunity for improvement. Creating construction elements, i.e. walls, floor, roof, etc. within either BIM enabled software is too simplistic to accurately account for heterogeneous construction layers. This is due to the construction assembly editing tool in both software packages only offering a basic homogenous construction build up. A potential way around this would be to create pre-set layers that included precalculated defaults for structural and insulation percentages. However, a weakness of this solution would be the quantity required to represent an appropriate range of structural configurations to gain a reasonably accurate percentage range.

This study also found that windows were the most accurately and consistently represented across all models. This is likely to be because there is very little room for variation compared to walls, roofs and floors. Additionally, thermal properties for windows are a well-recognised standard.

\subsection{Results - Whole Building Energy Simulation}

As expected the energy performance of the model using the software defaults is lower across both software packages. However, there is a significant gap between these two trends. This gap may potentially be caused by the difference between the default schedules and heating/cooling loads assigned to the model in each software according to its building types.

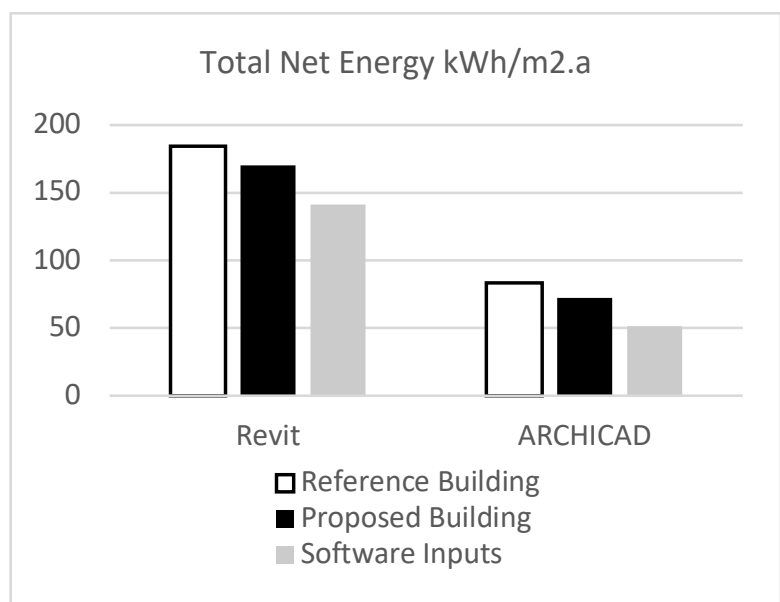

Figure 3: Whole Building Simulations in Revit and ARCHICAD

\subsection{Material Properties comparison}

In this case study, the software packages produced greater construction R-values compared to the proposed model, for the roof and wall elements which contained heterogeneous layers. However, as the difference between these R-values being so great, it is unlikely to be caused by the limitation of a homogenous calculation method alone. Instead, this difference has identified that the thermal properties of the materials that matched the description from the case study specification were significantly higher than the true thermal properties of the material used in New Zealand.

Table 1: Thermal Properties Glass Fibre Batts

\begin{tabular}{|l|l|l|}
\hline & $\begin{array}{l}\text { Conductivity } \\
(\mathrm{W} / \mathrm{mk})\end{array}$ & $\begin{array}{l}\text { Density } \\
\left(\mathrm{kg} / \mathrm{m}^{3}\right)\end{array}$ \\
\hline Wall - Glass Fibre Batt & & \\
\hline Specified True Material & 0.0388 & 14.0 \\
\hline Revit Material & 0.19 & 32.0 \\
\hline ARCHICAD Material & 0.033 & 50.0 \\
\hline Roof - Glass Fibre Batt & & \\
\hline Specified True Material & 0.0487 & 8.1 \\
\hline Revit Material & 0.19 & 32.0 \\
\hline ARCHICAD Material & 0.033 & 50.0 \\
\hline
\end{tabular}

Table 1 above shows that ARCHICAD had a closer thermal conductivity to the true material compared to Revit, however, Revit had a closer density. In both cases the thermal properties were not close enough to be considered an adequate representation of the true material.

\subsection{Redefining the Inputs: Formulae for Calculating} New Thermal Properties.

To compensate for the built-in R-value calculator being homogenous in both software packages, new material layers were calculated using the thermal properties of both insulation and wood. The new properties were calculated to account for the different ratios of each material that were prescribed in the proposed building where the R-values were calculated 
using the Iso-thermal Planes calculation method required by NZS 4214 .

Equations one and two demonstrate how new thermal properties were calculated. These were based off the principles of calculating isothermal planes. Fundamentally the purpose is to calculate an average of two properties that do not have an equal ratio.

In this study, equation 1 and equation 2 were used to redefine the thermal properties for the wall and roof heterogeneous layers. However, they could also be applied to the floor and any other part of the building that has a heterogeneous layer of any material type which needs to be converted into a format that can be used as an input for construction Rvalue calculations in ARCHICAD or Revit.

(1)

$$
\mathrm{TC}_{\mathrm{n}}=\frac{1}{\left[\left(\frac{\mathrm{R}_{\mathrm{T}}}{\mathrm{TC}_{\mathrm{T}}}\right)+\left(\frac{\mathrm{R}_{\mathrm{I}}}{\mathrm{TC}_{\mathrm{I}}}\right)\right]}
$$

(2)

Where..

$$
D_{n}=\frac{1}{\left[\left(\frac{R_{T}}{D_{T}}\right)+\left(\frac{R_{I}}{D_{I}}\right)\right]}
$$

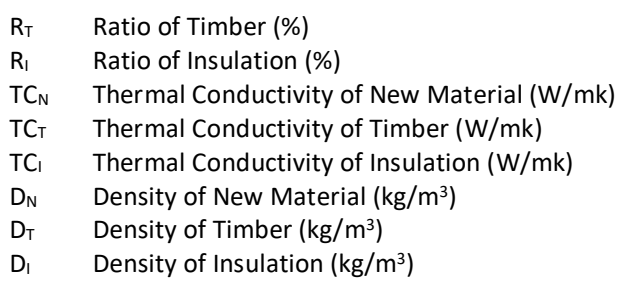

New Material Properties

\begin{tabular}{|l|l|l|}
\hline Description & $\begin{array}{l}\text { Thermal } \\
\text { Conductivity }\end{array}$ & Density \\
\hline $\begin{array}{l}\text { Wall } \\
\text { Timber } 18.7 \% \\
\text { Insulation } 81.3 \%\end{array}$ & 0.0444 & 17.10 \\
\hline $\begin{array}{l}\text { Roof } \\
\text { Timber } 12.1 \% \\
\text { Insulation } 87.9 \%\end{array}$ & 0.0525 & 9.19 \\
\hline
\end{tabular}

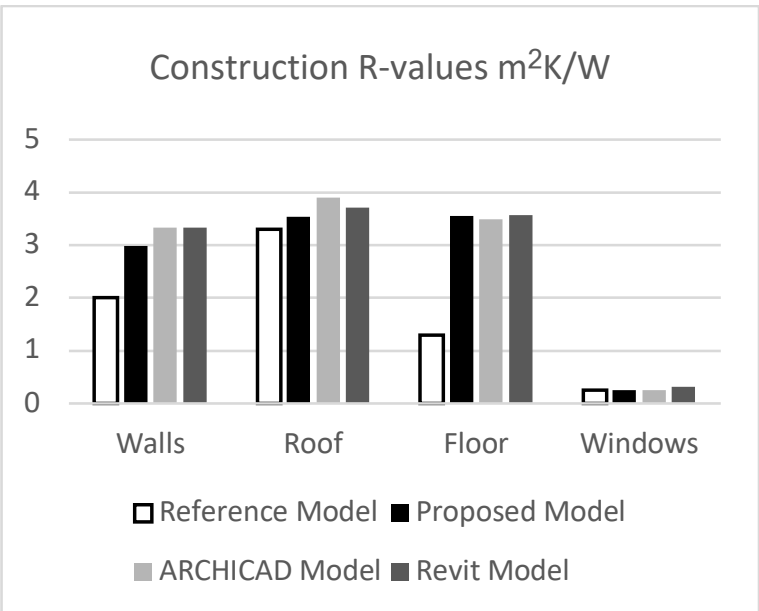

Figure 4: Updated Construction R-value calculations compared
Figure four shows that both ARCHICAD and Revit Rvalue calculators achieved a much closer result to the proposed R-value in both the wall and roof elements. This proves that defining a layer with the appropriate timber to insulation ratio and using thermal properties from New Zealand construction materials achieves a more reliable result.

\subsection{Impact of the New Materials on Whole Building Simulation}

Iterative simulations, shown in Figure five, simulate the case study with the updated construction R-values. These suggest that results now very closely match the proposed R-values. The simulation completed in Revit demonstrates the expected outcome, where the results from the updated model closely match the proposed model. However, the ARCHICAD simulation did not follow the same expected outcome, even though it's built in R-value calculator achieved results very close to the proposed R-values (Figure 4).

To examine the behaviour of the software, the Rvalue override function was used within ARCHICAD's energy evaluation settings (The same override function that was used for the reference and proposed simulations). The same R-value was put in and the "Structure's Heat Storage Mass" was assigned to the most appropriate option, i.e. "Timber Structure" for walls and roof. This simulation produced results closer to the proposed model, even though the same Rvalues were used. This suggests that in ARCHICAD there are other variables that are impacting the results that do not have the same impact in Revit. This is an interesting observation as both software packages claim validation through the ASHRAE 140 standard for international modelling software, yet, they respond to the same input differently. This is an area that merits further research.

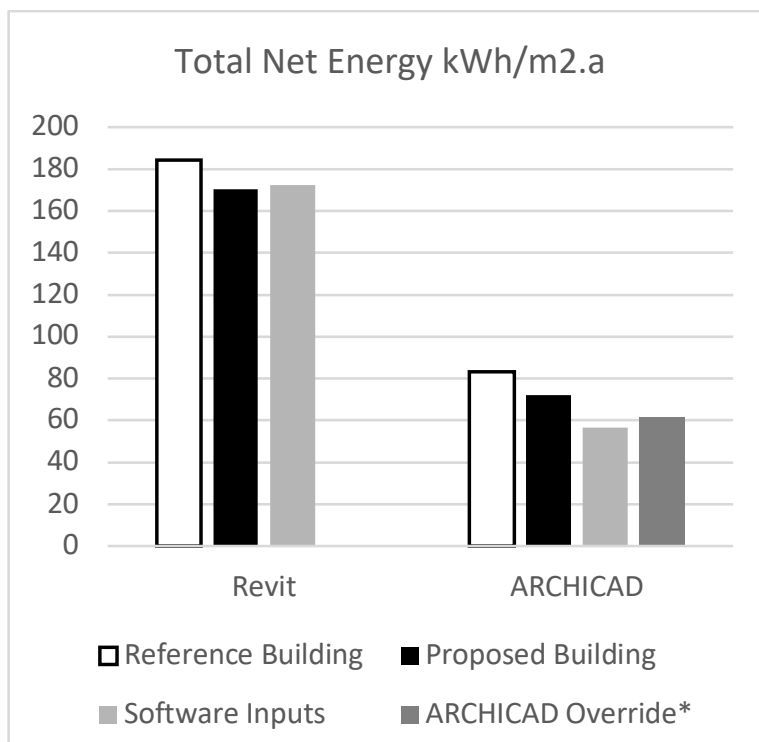

Figure 5: Whole Building simulations completed with the updated construction R-value calculations 


\section{CONCLUSION}

This study has identified that in both of the software packages examined the thermal properties of core construction materials are not an accurate representation of those used in New Zealand.

Although a homogenous construction R-value calculators, are built into both ARCHICAD and Revit, has the benefit of simplifying the calculation process, these values produce very optimistic results. This is due to the forced assumption of only a single material per layer. This is not an appropriate or accurate way of representing a timber framed house because the insulation is installed between the structural elements.

This paper tested a potential way to account for the thermal bridging of the timber structure, however, this method required external calculation and input. This removes the benefit of a semi-automated simulation platform as it requires the user to externally research the relevant materials, combine them using the formulae written into this paper and then create a new material within the software. This requires an expertise in energy modelling that is well above what is expected of an architect or designer in practice.

However, the results in this study indicate that there may be a potential to create a pre-set material library that is customised to the thermal properties of New Zealand materials that are combined using ratios that are relative to New Zealand construction techniques. A pre-set library of this kind has the potential to be loaded into software for both architects and designers alike, to achieve a more accurate and reliable simulation result of energy performance. Any pre-set library will need to be tailored for each software package and is an area that merits further investigation.

It should be noted that this research is not without its limitations:

The simulation results from Revit and ARCHICAD, identify that there are significant differences in the default assumptions each software package incorporates. These default assumptions include occupancy schedules and heating and cooling loads.

To test each software package for its accuracy, without the expertise of an energy analyst, default settings of the occupation profiles or building schedules were used. These differ for both software packages. The accuracy of these results based on these varying schedules is an area that merits further research.

The case study examined in this paper used relatively simple materials. A subsequent study may potentially develop a wider range of pre-set materials that take into account of the materials available in New Zealand and their relative ratios with respect to the common timber framed construction methods used in New Zealand.

Finally, this study does not take into consideration different microclimate conditions within New Zealand. These could potentially be used to establish how accurately the automated inputs predict differences in heating and cooling energy use requirements.

\section{REFERENCES}

1. Rosevear, M., \& Curtis, M. (2017). Physical characteristics of new houses 2015. Wellington: BRANZ.

2. Thompson, K. (2012, August/September). Making the most of BIM. BUILD, 39.

3. Bazjanac, V. (2008). IFC BIM-Based Methodology for Semi-Automated Building Energy Performance Simulation. CIB-W78 25th International Conference on Information Technology in Construction. Santiago, Chile: Lawrence Berkeley National Lab.

4. New Zealand Building Code (NZBC). (2007).

5. Laine, T., Hanninen, R., \& Karola, A. (2007). Benefits of BIM in the Thermal Performance Management. Proceedings of the Building Simulation. Helsinki.

6. Attia, Shady. (2013) Tool for design decision making: Zero energy residential buildings in hot humid climate ; 13 th Conference of the International Building Performance Simulation Association IBPSAA: Chambery.

7. Bum Kim , J., Jeong, W., Clayton, M. J., Haberi, J. S., \& Yan, W. (2015). Developing a physical BIM library for building thermal energy simulation. In M. J. Skibniewski, Automation in Construction (Vol. 50, pp. 16-28). USA: Elsevier.

8. NZS 4218 (2009). Thermal insulation - housing and small buildings.

9. NZS 4214 (2006). Methods of determining the total thermal resistance of parts of buildings.

10. GRAPHISOFT. (2017). Energy Evaluation Workflow: Overview. Retrieved 2018.

11. Page, I.C, and Fung, J. BRANZ SR214 (2009) Housing life cycle and sustainability Part One I.

12. Bryson, K. (2017). The New Zealand Housing Preferences Survey: Attitudes towards mediumdensity housing. Wellington: BRANZ. 